\title{
Utilization of TRIZ to Solve the Quality Problems in Semiconductor Etching Process
}

\author{
Hong Kyun Shim ${ }^{1}$, Yong Won Song ${ }^{2}$, Kwang Jun Lee ${ }^{3}$ \\ ${ }^{1}$ Engineer, SK Hynix Semiconductor Co., Ltd., 20, SK-ro, Heungdeok-gu,Cheongju-si, \\ Chungcheonbuk-do, Korea, hongkyun.shim@sk.com \\ ${ }^{2}$ Professor, Dept. Nano \& Semiconductor Engineering, Korea Polytechnic Univ., Sangidaehak-ro, \\ Siheung-si, Gyeonggi-do, Korea, ywsong@kpu.ac.kr \\ ${ }^{3}$ Engineer, SK Hynix Semiconductor Co., Ltd., 2091, Gyeongchung-daero, Bubal-eub, Icjeon-si, \\ Gyeonggi-do, Korea, Kwangjun.lee@sk.com
}

Corresponding author: Yong Won Song

\begin{abstract}
The production of high quality semiconductors have been incessantly contributing to the development of advanced technological devices answering many of today's industrial and societal needs. This paper presents an example of problem solving in the equipment front-end module (EFEM)[1] in the Fab etching process, where wafers are transferred under atmospheric pressure. Toxic gaseous impurities called fumes are generated upon completion of wafer processing. Because of these fumes, problems such as internal corrosion in the EFEM and wafer quality degradation may occur. The root causes of fume[2] retention were confirmed through functional analysis, and the technical contradictions were analyzed to reveal that fumes were not completely discharged owing to internal obstacles and air current problems. From the functional interaction analysis, the functions of each part were defined and analyzed. Further, a case discussion for solving the problems caused by inadequate fume clearance is presented using the TRIZ technique, specifically the 40 inventive principles on invention, separation rules, and trimming. The aim of this study is to demonstrate how TRIZ can effectively help to solve problems in industrial applications and thereby provide economic benefits.
\end{abstract}

Keywords: Fume, TRIZ, Equipment Front End Module(EFEM), Exhaust Port, Air Flow, Trimming

\section{Introduction}

Since the advent of the Fourth Industrial Revolution, the semiconductor industry has witnessed rapid developments. Simultaneously, considerable efforts have been made to advance semiconductor technologies and improve the output product quality. Corporations are engaged in a fierce competition in the developing semiconductor industry. Many products of high quality must be produced in limited time and with a low cost. As the technology becomes more advanced the production process becomes more complicated, more problems arise. Thus, a limitless reformation is required to mass produce high quality semiconductors to address the issues.

\subsection{TRIZ}

The terms TRIZ, derived from Russian words "Teoriya Resheniya Izobretatelskikh Zadatch", stands

Received: September 24, 2020; 1st Review Result: November 12, 2020; 2nd Review Result: December 29, 2020 Accepted: January 25, 2021 
for "Theory of Inventive Problem Solving". This theory was developed by Genrich Altshuller, who analyzed about two hundred thousand patents registered in the Russian Patent Office and found the common principles of creatively solving problems[3]. It is a well-established system of tools for innovative problem solving, idea generation, failure analysis, and prediction[4][5]. TRIZ helps to logically, scientifically, and systematically deduct and define methods of problem-solving. In this thesis, component analysis and cause-effect chain analysis (CECA) were used out of numerous TRIZ problem analyzing tools to analyze the root cause of the problems. Through contradiction formulation, 40 inventive principles, separative principles, standard principles were used. With the help of trimming, the greatest effect was achieved with minimal changes.

\subsection{Problem Situation}

The semiconductor manufacturing processes are broadly categorized into eight steps[5], namely wafer manufacturing, oxidation, photoresist coating and liftoff, etching, thin film and vapor deposition, metal wiring, electrical die encasing, and sorting and packaging. The etch process, one of the processes for manufacturing a semiconductor, exposes a wafer using photo register during the photo process. It is a process for etching oxide films by forming a plasma using a large number of gases and pressure.

The fabrication process is then continued by transferring the wafer from the equipment front-end module (EFEM)[Fig. 1] under atmospheric pressure to the process module in the vacuum state; then, etching is performed on the wafer using the chemical reaction between gas and plasma in vacuum at a pressure below 100 mTorr. The completed wafer is then transferred to the atmospheric pressure area again for retrieval[Fig. 2]. As shown in [Fig. 1], impurities generated after the etching process do not react in the vacuum state, but cause chemical reactions upon contact with air in the EFEM in the atmospheric pressure area. As a result, toxic gaseous impurities called fumes are generated and diffused within the manufacturing area.
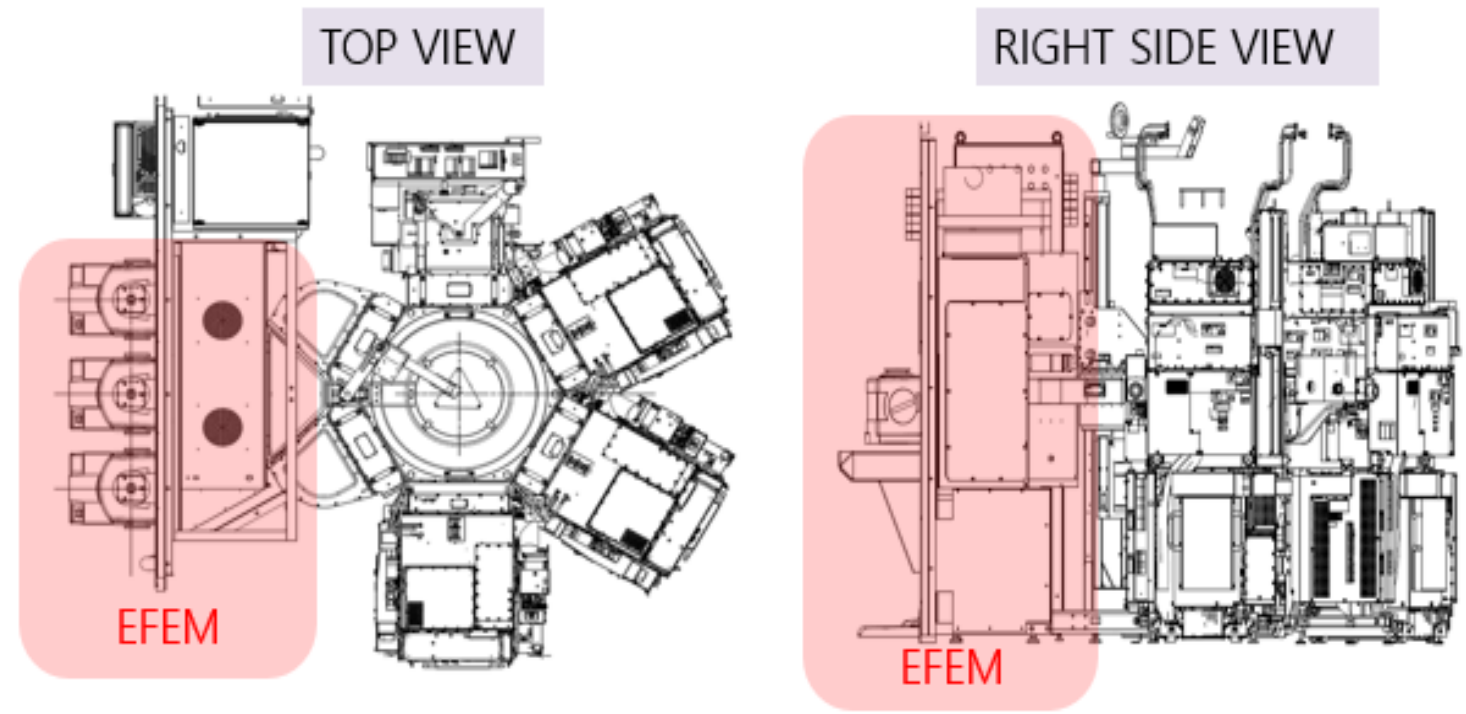

[Fig. 1] Schematic of the EFEM

The fumes generated during the fabrication are retained within the EFEM and are diffused therein as they experience state changes from vacuum to atmospheric pressure. Hence, the fumes accumulate inside the EFEM and cause internal corrosion over time, resulting in the formation of solid crystals as the fumes condense in vulnerable parts [Fig. 3]. The crystals may also fall on the upper side of the wafers sometimes, causing quality problems in the wafer. 


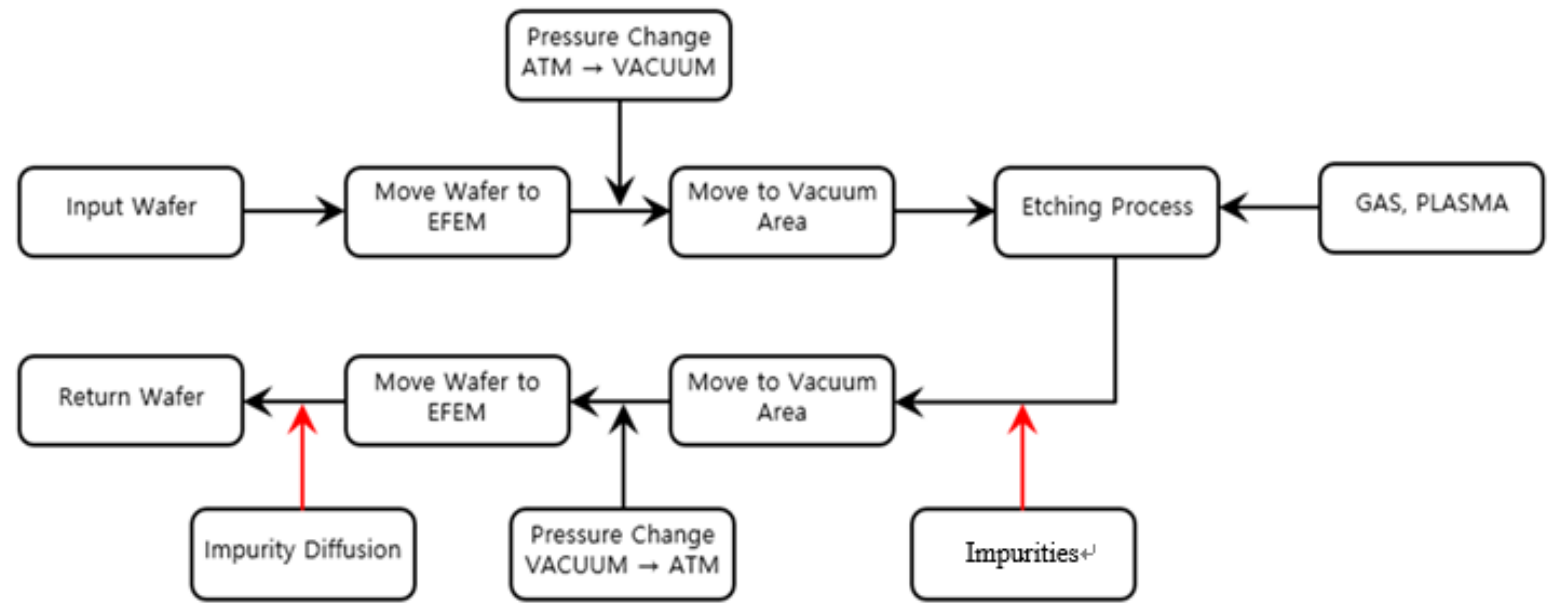

[Fig. 2] Schematic of the EFEM

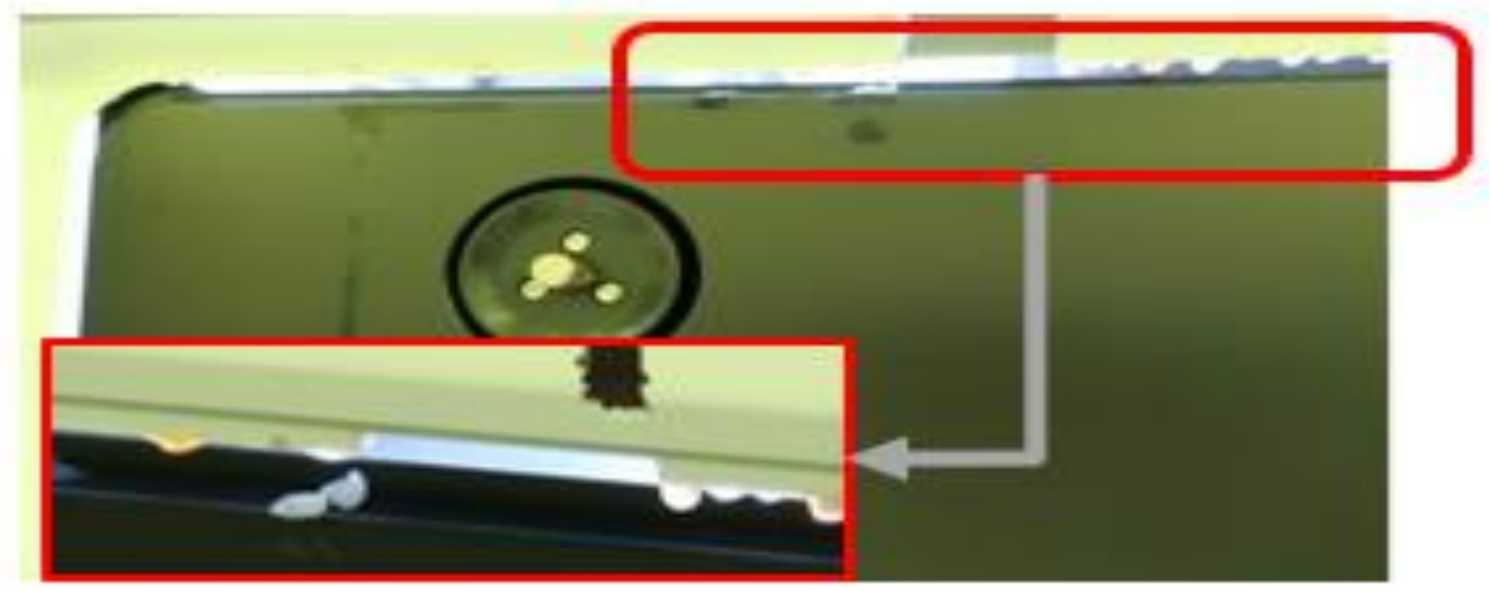

[Fig. 3] Fume Crystals Formed in the EFEM

\subsection{Regulations and Restrictions}

There are certain process conditions that can or cannot be changed due to process specificity and resource characteristics while solving the problem of fume retention. These regulations and restrictions may be summarized as follows.

[Table 1] Regulations and Restrictions in Solving the Fume Retention Problem

\begin{tabular}{|c|c|}
\hline \multirow{3}{*}{ Restrictions } & Pressurized state inside the EFEM $(3 \mathrm{~Pa})$ \\
\cline { 2 - 3 } & Recipe change impossible in the middle of a process \\
\cline { 2 - 3 } Changeable conditions & Number of fans and filter types \\
\cline { 2 - 3 } & Number of exhaust ports in conditions where pressurized state is maintained \\
\cline { 2 - 3 } & Change in flow recipe that does not affect the production volume \\
\cline { 2 - 2 } & Number of air flow channels inside the EFEM \\
\hline
\end{tabular}




\section{Problem analysis}

\subsection{System Function Analysis}

From a functional point of view, the components inside the EFEM that are targeted at solving the problem are the intake port, fan, filter, robot, exhaust port, load port, front opening unified pod (FOUP), wafer, and air flow. As shown in Figure 4, the subsystem resources are as follows. The intake port supplies external air inside the EFEM. The fan supplies external air through the filter, which purifies the air and supplies it to the EFEM. A robot moves the wafer, which is a Chip base for producing semiconductors, in the EFEM part. The loadport connects the EFEM and foup, which is a space for the wafer to wait. The exhaust port discharges the air that has passes through the filter to the outside. The airflow current inside the EFEM moves in a downward flow, which is the designated passage for air movement based on supply and exhaust of air[6].
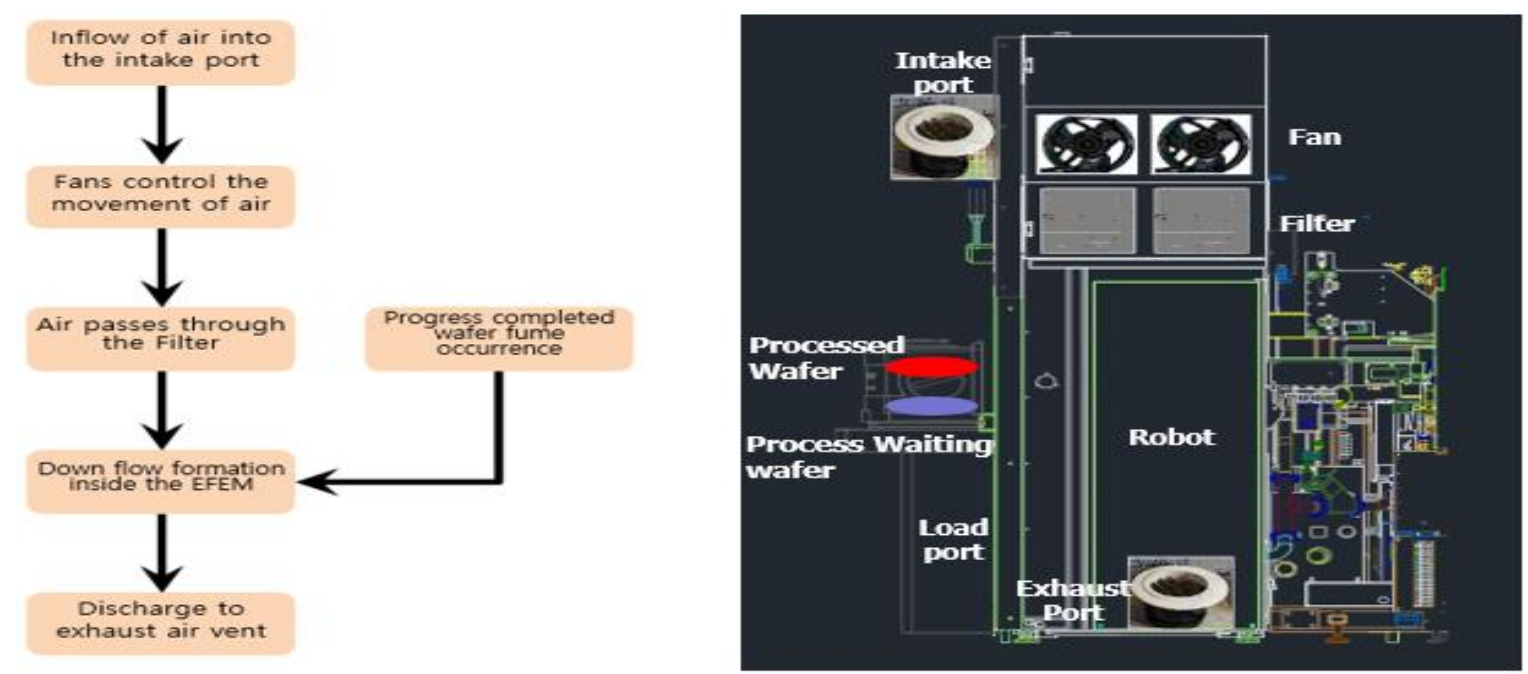

[Fig. 4] Discharge Process of Air Inside the EFEM

\subsection{Cause-effect Chain Analysis (CECA)}

The CECA analysis, which is a TRIZ tool, is a method that systematically analyzes diverse causes of problems[6]. It is used to closely analyze the sedimentation process, as shown in Figure 5. It also analyzes the Operation Time (OT) or when harmful actions occur in a cause-effect relationship, as well as the Operation Zone (OZ) or where the problems occure, thus, makes the problem-solving method easier and more accurate[7]. The inner components were confirmed and the OZ and OT were defined according to the exhaust process. The operating zone $(\mathrm{OZ})$ and operating time $(\mathrm{OT})$ of the problem generation elements were defined based on the fume discharge process and verification of the internal components. The OT was defined as the time occurrence of fumes from a wafer. Fumes are generated during the wafer processing and are reduced by about $80 \%$ through appropriate high-temperature thinfilm processing called strip process[8][9] because the fumes are easily activated at high temperatures. However, this process is not applicable to the current scenario because it does not satisfy the restriction and changeable condiction, as shown in [Table 1], owing to the increase in production volume and work hours as a result of addition of the new processes. The OZ was defined as that region around the load port where the fumes are not discharged. Here, the fumes remain stagnant because they are not discharged rapidly, and these fumes condense in vulnerable places within the EFEM owing to 
temperature and humidity changes, thereby generating fume crystals over time.

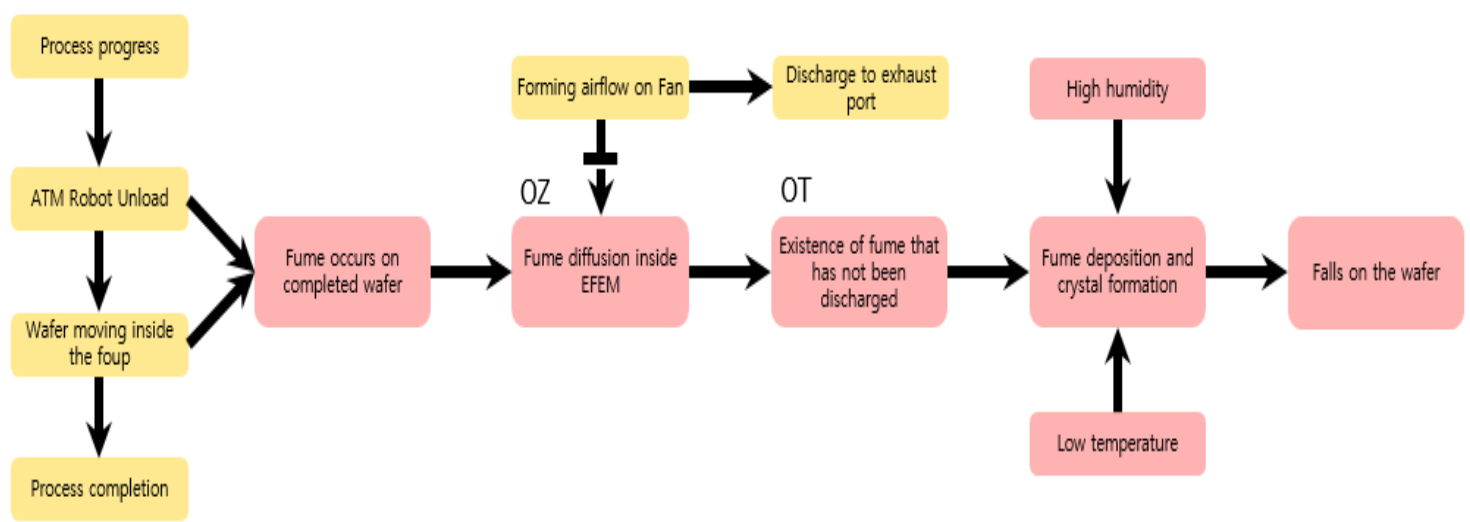

[Fig. 5] Cause-effect Chain Analysis

\subsection{Analysis of Root Causes}

To assess the conditions within the EFEM for which fumes are not discharged, software simulations[Fig. 6](SOLIDWORKS) were conducted under the same conditions. The simulation results verified that the airflow direction was curved rather than linear from the upper to the bottom and that the airflow that was not discharged was retained within the EFEM, where it impinged on the perimeter. It was noted that abnormal airflows were formed in the direction opposite the area where the problem occurred during airflow curving. The cause of such abnormal airflow was attributed to the process unit inside the EFEM, which prevented a linear airflow path. Thus, the airflow around the load port was affected and that required for fume discharge did not exist.

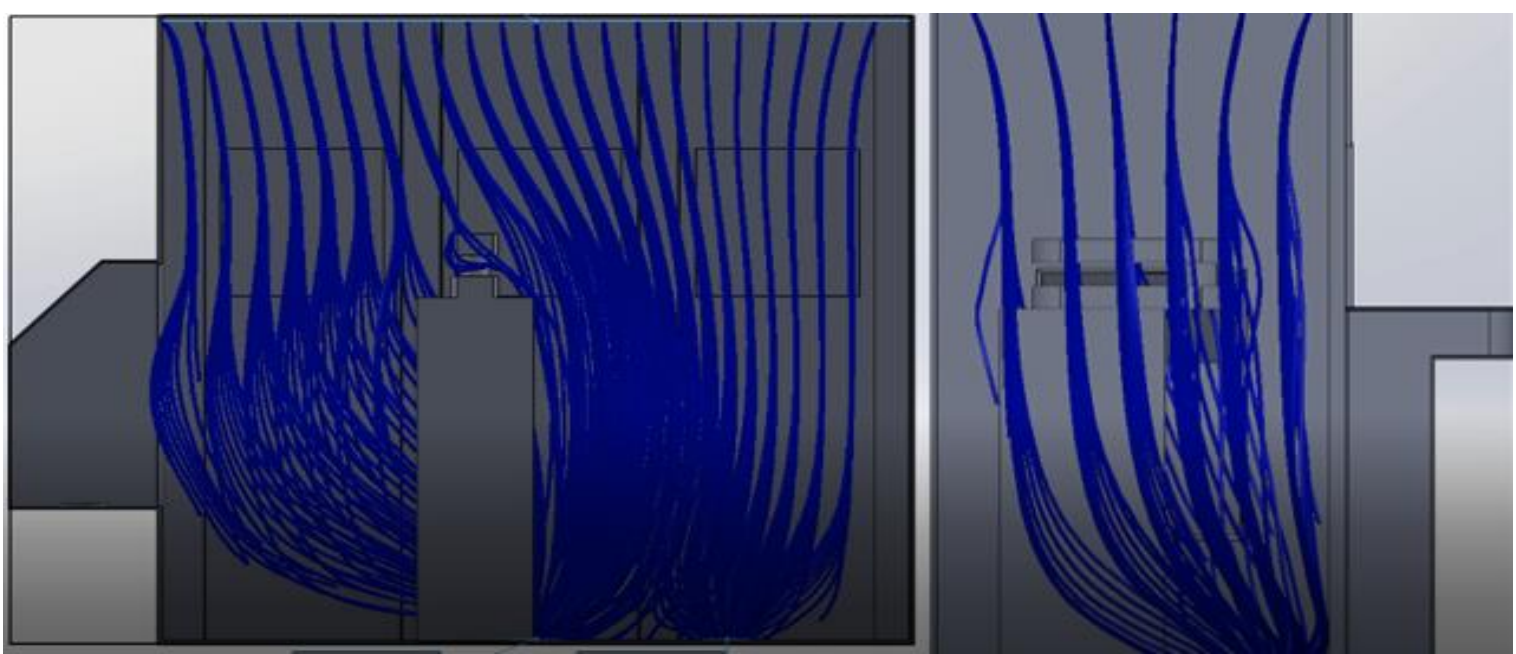

[Fig. 6] Airflow Inside the EFEM (schematic depiction using SOLIDWORKS)

\subsection{Technical Contradiction}

Technological contradiction[10][11] is a problem where one characteristic of a system is improved, another characteristic deteriorates, or a new problem occurs. The technical contradictions(TC)[Fig. 7] were defined as tasks through the CECA. TC 1 indicates that although fume discharge occurring within the EFEM are strengthened with stronger airflows, the low internal pressure may draw any external particles into the EFEM. TC 2 indicates that although the fume discharge within the EFEM worsens with weaker air flows, the high internal pressure may block the inflow of external particles. TC 2 was 
selected herein because the inherent function of the EFEM was to prevent inflow of external impurities into the equipment.

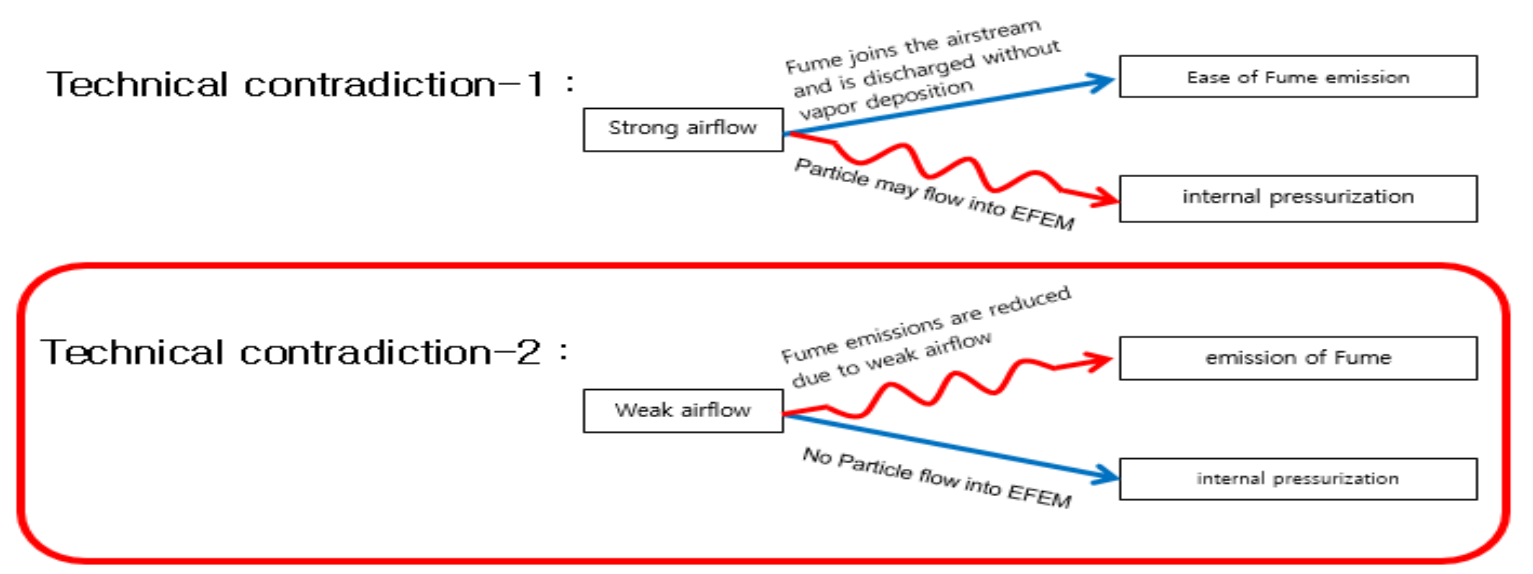

[Fig. 7] Schematic Depiction of Technical Contradictions

\subsection{Deepening the Technical Contradiction}

In this study, the fume retention problem was solved by deepening the technical contradictions, which is described as follows. Although inflow of external particles is stopped because of the increase in the internal pressure of the EFEM without exhaust, the fumes are not discharged sufficiently, thereby deepening the occurrence of internal deposition and corrosion. [Fig. 8] A certain $\mathrm{X}$ element, which facilitates the discharge of fumes while maintaining the pressurized state by adjusting the exhaust inside the EFEM, should be define and applied. Although the fumes are generated from the wafers, no problems are caused when the fumes are completely discharged. When summarizing the OZ and OT, it was concluded that the fumes around the load port where the process-completed wafers are retained for the greatest amount of time should be removed by an appropriate exhaust mechanism.

T2

When the completed wafer is not in foup

\section{T1}

When the Fume generated from the completed wafer does not join with the airflow and is not discharged

[Fig. 8] OT of Deepening Technical Contradiction

\subsection{Substance-field Resource Analysis}

The resource analysis needed to solve the fume problem was also conducted[Table 2]. Resources were divided into two types as those influencing the $\mathrm{OZ}$ and those with external concerns. Airflows are formed by the supply at the upper side of the EFEM and the exhaust at its lower side. The changes in the supply are considered under the regulations and restrictions, and the supply cannot be changed. Although addition and expansion of exhaust ports inside the EFEM are needed, indiscriminate addition of exhaust ports is not possible because it can change the pressurized state inside the EFEM. However, airflows should be controlled using the exhaust as it is a significant influence. Thus, the change in airflow can be expressed by the change in the number of exhausts. The X element of the technical contradiction was thus set to the exhaust port. 
[Table 2] Substance-field Resource Analysis

\begin{tabular}{|c|c|c|c|c|c|}
\hline $\mathrm{N}$ & $\begin{array}{l}\text { Location of } \\
\text { the resource }\end{array}$ & $\begin{array}{l}\text { Name of the } \\
\text { resource }\end{array}$ & $\begin{array}{l}\text { Type of the } \\
\text { resource }\end{array}$ & Quantity & $\begin{array}{l}\text { Inherent characteristics of the substance and } \\
\text { source of field }\end{array}$ \\
\hline 1 & $\mathrm{OZ}$ & FAN & Useful & $1 \mathrm{EA}$ & Mechanical-Wind \\
\hline 2 & $\mathrm{OZ}$ & FILTER & Useful & $1 \mathrm{EA}$ & Mechanical-Contact \\
\hline 3 & $\mathrm{OZ}$ & ROBOT & Neutral & $1 \mathrm{EA}$ & Mechanical-Mechanical reaction \\
\hline 4 & $\mathrm{OZ}$ & Exhaust port & Useful & 2EA & Mechanical-Wind \\
\hline 5 & $\mathrm{OZ}$ & LOAD PORT & Neutral & 3EA & Mechanical-Mechanical reaction \\
\hline 6 & $\mathrm{OZ}$ & FOUP & Neutral & Small amount & Mechanical-Mechanical reaction \\
\hline 7 & $\mathrm{OZ}$ & Air intake part & Neutral & $1 \mathrm{EA}$ & Mechanical-Wind \\
\hline 8 & $\mathrm{OZ}$ & WAFER & Neutral & Small amount & Chemical \\
\hline 9 & $\mathrm{OZ}$ & Internal air & Useful & Large amount & Mechanical-Wind \\
\hline 10 & $\mathrm{OZ}$ & FUME & Harmful & Large amount & Chemical-Chemical reaction \\
\hline 11 & External & External air & Neutral & large amount & Machine \\
\hline
\end{tabular}

\section{Problem solving}

\subsection{Contradiction, Invention Principle, and Solution Derived through Separation Principle}

One measure to solve the above problem was by combining the technical and physical contradictions. The solution measure was established by applying the principles of invention[12] based on the technical contradictions. Because the feature that is improved is the exhaust power, a tension pressure was selected in this study. Here, the worsening feature was set to the stability of the object because the worsening characteristic was the internal pressure. The principles of invention chosen from the contradiction matrix were No.35 transformation of properties, No33. homogeneity, No.2 extraction and separation, and No.40 composite materials. The solutions were established through the principles of invention in [Table 3] and separation in [Table 4][Fig. 9].

[Table 3] Solutions through Principles of Invention using the Contradiction Matrix

\begin{tabular}{|c|l|l|}
\hline $\begin{array}{c}\text { Contradiction } \\
\text { matrix }\end{array}$ & Worsening feature 13. Stability of the object. & Solutions \\
\hline \multirow{3}{*}{$\begin{array}{c}\text { Improving } \\
\text { feature } \\
\begin{array}{c}\text { 11. Tension } \\
\text { pressure }\end{array}\end{array}$} & 35. Transformation of properties & Substance input that can neutralize fumes \\
\cline { 2 - 3 } & 2. Extraction and separation & \\
\cline { 2 - 3 } & 40. Composite materials & Discharge of localized fumes by separating the two exhaust ports \\
\hline
\end{tabular}


[Table 4] Solution using the Principles of Separation

\begin{tabular}{|c|c|}
\hline Principles of separation & Solutions \\
\hline Time separation & Discharge is facilitated to prevent deposition of fumes. \\
\hline Spatial separation & Discharge ports are separated and installed locally around places where fumes were deposited. \\
\hline Condition separation & Process is improved to prevent fume generation. \\
\hline Partial and entire separation & Discharge ports are separated partially rather than having all discharge ports on the lower side. \\
\hline
\end{tabular}

\begin{tabular}{|c|c|c|}
\hline Principle & Expressed in general terms & $\begin{array}{c}39 \text { Expressed by generalization } \\
\text { parameters }\end{array}$ \\
\hline Deteriorating character & Fume Discharge & 11. Tension Pressure \\
\hline $\begin{array}{c}\text { Characteristics you } \\
\text { want to improve }\end{array}$ & Internal Pressure & 13. Stability of the object. \\
\hline $\begin{array}{c}\text { Recommended } \\
\text { invention principle }\end{array}$ & 35. Transformation of properties / 33. Homogeneity / 2. Extraction and \\
separation / 40. Composite materials
\end{tabular}

\begin{tabular}{|c|c|c|c|c|c|c|c|}
\hline \multirow{5}{*}{ 꽁 } & \multirow[b]{2}{*}{ No } & \multirow[b]{2}{*}{ Principle } & \multirow[b]{2}{*}{ Idea } & \multicolumn{4}{|c|}{ Idea evaluation $(\Theta: 5,0: 3, \Delta: 1)$} \\
\hline & & & & Ideality & $\begin{array}{c}\text { Conflict } \\
\text { resolutio } \\
\mathbf{n}\end{array}$ & Reality & Score \\
\hline & 1 & $\begin{array}{l}\text { Transformation } \\
\text { of properties }\end{array}$ & $\begin{array}{l}\text { Substance input that can neutralize } \\
\text { fumes }\end{array}$ & $\Delta$ & $\bullet$ & $\Delta$ & 7 \\
\hline & 2 & $\begin{array}{l}\text { Extraction and } \\
\text { separation }\end{array}$ & $\begin{array}{l}\text { Discharge of localized fumes by } \\
\text { separating the two exhaust ports }\end{array}$ & $\bullet$ & 0 & $\bullet$ & 13 \\
\hline & 3 & $\begin{array}{l}\text { Spatial } \\
\text { separation }\end{array}$ & $\begin{array}{l}\text { Discharge ports are separated and } \\
\text { installed locally around places where } \\
\text { fumes were deposited. }\end{array}$ & - & $\Delta$ & $\bullet$ & 11 \\
\hline
\end{tabular}

[Fig. 9] Idea Inference and Selection

\subsection{Derived Final Solution (Trimming)}

The final solution was derived on the basis of duplicate items using the principles of invention and separation. The final solution presented was to separate the exhaust ports, which was the X element, and install them locally around the places where fume deposition occurred. Then, airflow simulations were conducted, and the results exhibited that the same downward flow of air was maintained even when the two exhaust ports on the lower side were reduced to one. Based on the trimming Rule 3[13][Fig. 10], function carrier can be trimmed if another component can perform its useful function, i.e., exhaust port 2 on the lower side was trimmed and utilized differently. In this study, the exhaust port based on the fume was separated from the exhaust of the local part. By utilizing one Trimmed exhaust port to maintain internal pressure, a new exhaust port is created and installed to suppress Fume generation and accumulation in locally vulnerable areas, and exhaust by Down Flow airflow. This made it possible to respond to various vulnerable areas [Fig 11]. 


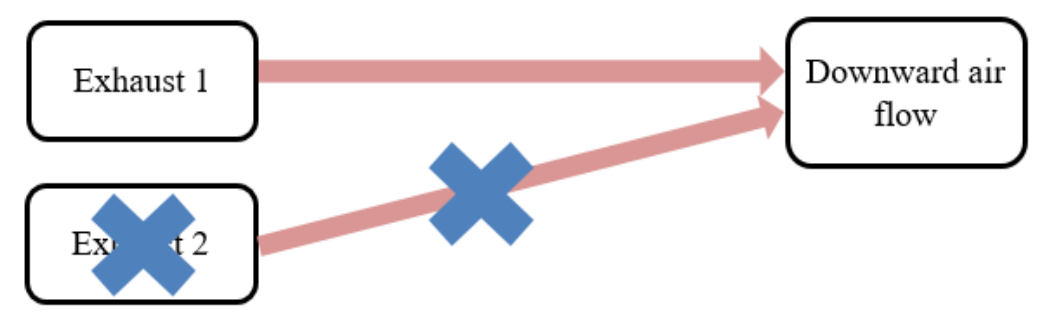

[Fig. 10] Modification based on Trimming Rule 3

$\langle$ As-is >
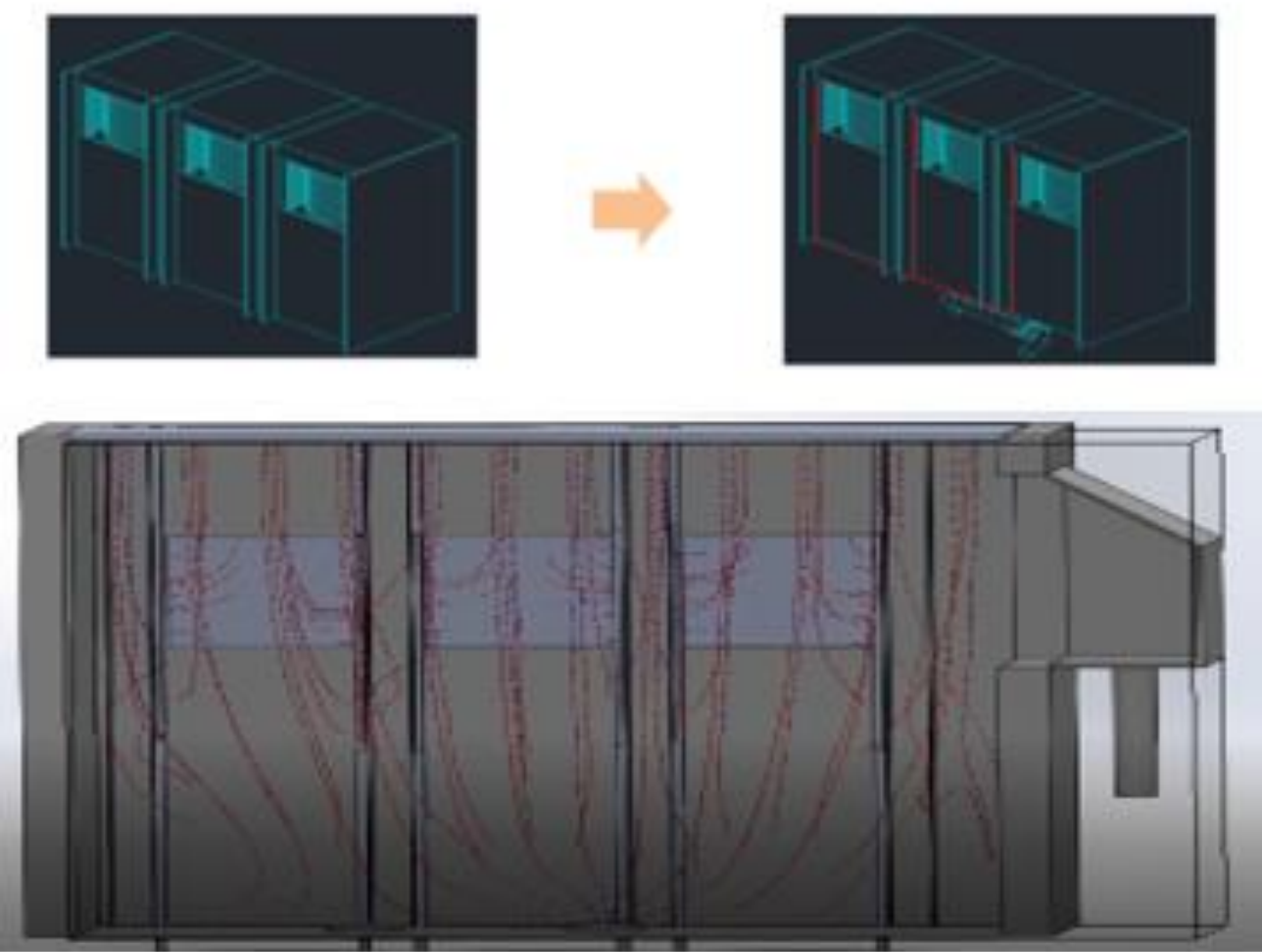

[Fig. 11] Schematic of Airflow through the Devised Exhaust Port (Using by SOLID WORKS)

The above changes confirmed lowering of specific gas concentrations, which were the main components of the fumes[Fig. 12]. As the toxic fumes decreased, the adverse effects on workers' health were minimized. The economic benefit of this was that the washing hour per quarter was reduced from $240 \mathrm{~min}$ to $0 \mathrm{~min}$, and the human resource loss reduced to zero as the washing procedure by workers became unnecessary. The number of wafers lost based on the quality issue reduced from four to zero on a monthly basis. This benefit translates to around 1 billion KRW per quarter through reduction of wafer loss, contribution to production due to shortened washing hours, and reduction of human resource loss[Fig. 13].

\section{Conclusions}

The solution obtained using TRIZ has been applied to other semiconductor equipment to this day, confirming its utility. This work could be a learning experience that problems can occur in indirect areas as well as in direct process progress areas. The example presented in this work is a proof that the TRIZ 
methodology analyzes problems accurately, and provides faster and easier solutions than traditional troubleshooting tools. This study has found that TRIZ theory can reinforce problem-solving abilities and generate creative ideas.
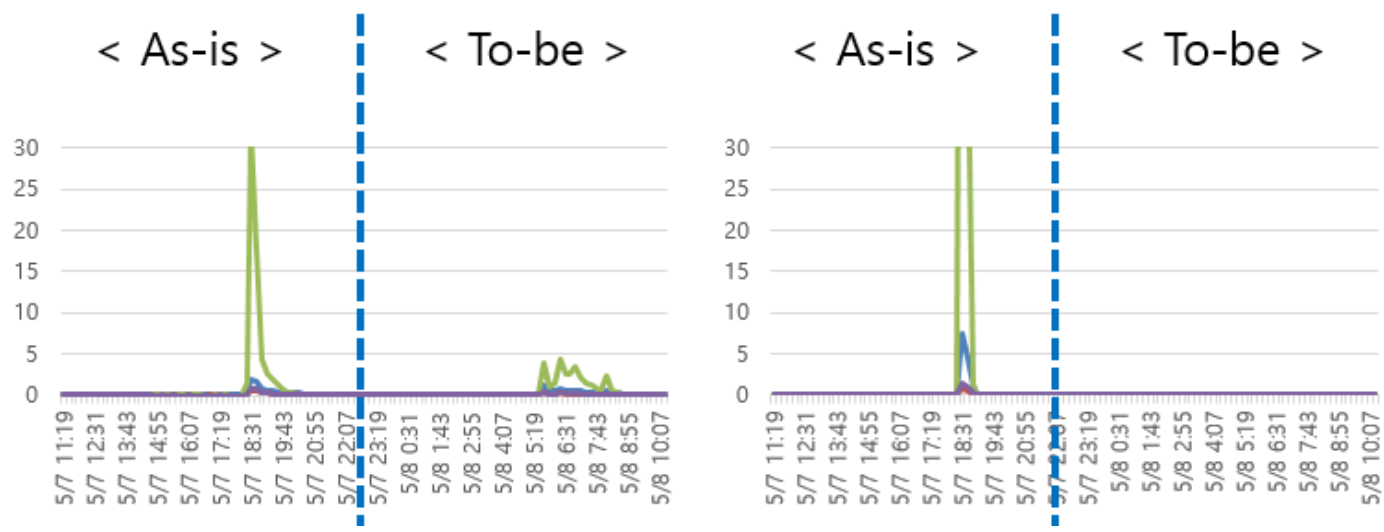

[Fig. 12] Detection of Specific Gas Concentration
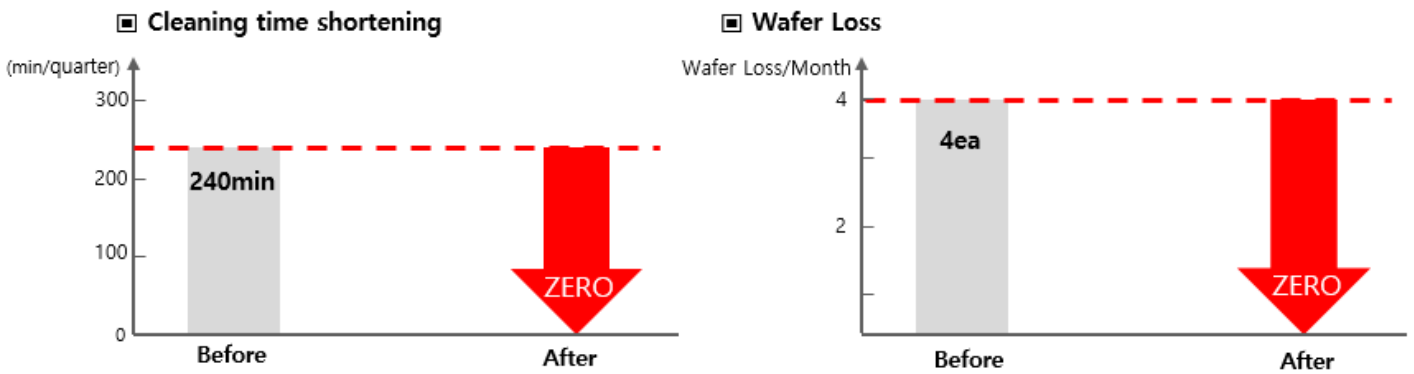

[Fig. 13] Results of Improvement Activity

\section{Acknowledgments}

This research was supported by Basic Science Research Program through the National Research Foundation of Korea (NRF) funded by the Ministry of Education (2018R1D1A1B07049244).

\section{References}

[1] B. J. Woo, Equipment Front end Module, EFEM, US20190304819A1, (2019)

[2] http://www.ilpi.com/msds/ref/fume.html, Feb 02 (2020)

[3] H. Y. Kim, Introduction of TRIZ Techniques for Creative Problem Solving, Korean Geosynthetics Society, (2011), Vol.10, No.4, pp.25-31.

[4] H. J. Kim, Another name for creativity TRIZ, INFINITYBOOKS, (2009)

[5] http://www.samsungsemiconstory.com/2206, Jan 16 (2020)

[6] Y. W. Song, Learn TRIZ, Quality and Creativity, KSA, Sep (2015)

[7] S. C. Kim, G. Schelske, FOUP purge performance improvement using EFEM flow converter, 2016 27th Annual SEMI Advanced Semiconductor Manufacturing Conference (ASMC), IEEE, pp.6-11, 16-19 May, (2016), Saratoga Springs, NY, USA, DOI: 10.1109/ASMC.2016.7491075 
[8] http://www.samsungsemiconstory.com/546, Dec 24 (2013)

[9] M. M. Rashad, M. M. Hessien, E. A. Abdel-Aal, K. El-Barawy, R. K. Singh, Transformation of silica fume into chemical mechanical polishing (CMP) nano-slurries for advanced semiconductor manufacturing, Powder technology, (2011), Vol.205, No.1-3, pp.149-154

[10] E. K. Kim, B. C, Koo, A Study of Applying TRIZ in Software Development, Journal of the Korea Institute of Information and Communication Engineering, (2014), Vol.18, No.3, pp.719-726, https://doi.org/10.6109/jkiice.2014.18.3.719

[11] Li Dan, Zhang Yu, Zhang Naiqi, Yin Yu, Using TRIZ Theory to Design and Analyze the Forest Environmental Factors Monitoring Platform, International Journal of Smart Home, (2016), Vol.10, No.4, pp.1-14.

[12] T. Y. Kim, J. H. Kim, Y. T. Park, Improving the Inventive Thinking Tools Using Core Inventive Principles of TRIZ, Journal of the Korean society for Quality Management, (2018), Vol.46, No.2, pp.259-268, https://doi.org/10.7469/JKSQM.2018.46.2.259

[13] Y. W. Song, K. M. Kim, S. H. Kim, Creative Problem Solving Theory TRIZ, KSA Media, pp. 304, (2017) 